\title{
Pancreatitis aguda inducida por SARS-CoV-2: Serie de 3 casos
}

\author{
[SARS-CoV-2-induced acute pancreatitis: Series of 3 cases]
}

\begin{abstract}
Dra. Ana Karina Coronado P. ${ }^{1}$, Dr. Carlos Daza T. ${ }^{2}$, Dra. Kira Alvarado ${ }^{3}$
${ }^{1}$ Médico Especialista en Gastroenterología pediátrica y nutrición, Hospital Materno Infantil José Domingo de Obaldía, ${ }^{2}$ Médico Especialista en Infectología pediátrica, Hospital Materno Infantil José Domingo de Obaldía, ${ }^{3}$ Médico Especialista en Gastroenterología pediátrica y nutrición, Hospital Materno Infantil José Domingo de Obaldía.

Correspondencia:Dra. Ana Karina Coronado P.MD. Correo electrónico: karina_coronado@hotmail.com
\end{abstract}

Recibido: 21 de enero de 2021

Publicado: 1 de abril de 2021

Cita: Coronado AK, (2020), Pancreatitis aguda inducida por SARS-CoV-2: Serie de 3 casos, DOI: 10.37980/im. journal.rspp. 20201737

Palabras clave: dolor abdominal, lipasa, pancreatitis aguda, SARS-CoV 2.

Key words: abdominal pain, lipase, acute pancreatitis, SARS-CoV 2.

Reproducción: Artículo de acceso libre para uso personal e individual. Sujeto a derechos de reproducción para otros usos.

Conflictos de interés: Los autores declaran no tener conflictos de interés.

Financiamiento: El autor no declara fuentes externas de financiamiento asociados a este trabajo.

\section{Resumen}

Desde la aparición de los primeros casos por Síndrome respiratorio agudo severo 2 (SARS-CoV 2) surge el desafío de comprender su amplio espectro clínico de síntomas y secuelas, siendo una prioridad para el sistema de salud. Los síntomas más frecuentes son fiebre, tos, mialgia y dificultad respiratorio. Sin embargo, se ha descrito que el SARSCoV 2 puede presentarse con síntomas gastrointestinales. Entre ellos hiporexia, náuseas, vómitos, diarrea, aumento de transaminasas y pancreatitis. Presentamos una serie de 3 casos consecutivos de pancreatitis aguda por COVID-19 en pacientes pediátricos, en el período de agosto-noviembre de 2020, en un hospital de referencia de tercer nivel (Hospital Materno Infantil José Domingo De Obaldía).

\section{Abstract}

Since the appearance of the first cases of severe acute respiratory syndrome 2 (SARSCoV 2), the challenge arises to understand its wide clinical spectrum of symptoms and sequelae, being a priority for the health system. The most common symptoms are fever, cough, myalgia, and shortness of breath. However, it has been reported that SARS-CoV 2 can present with gastrointestinal symptoms. These include hyporexia, nausea, vomiting, diarrhea, increased transaminases, and pancreatitis. We present a series of 3 consecutive cases of acute pancreatitis due to COVID-19 in pediatric patients, in the period August-November 2020, in a third-level referral hospital (Hospital Materno Infantil José Domingo De Obaldía).

\section{Introducción}

Desde los primeros casos del síndrome respiratorio agudo severo producido por SARS-CoV 2 que causa la enfermedad de COVID-19, surge el desafío de comprender su amplio espectro clínico.

Aunque la COVID-19 es considerada una enfermedad respiratoria, cada día surge mayor evidencia de ser multisistémi$\mathrm{ca}$, donde el sistema gastrointestinal parece importante en la patogenia y el pronóstico de la enfermedad. ${ }^{1,2}$

La pancreatitis aguda (PA) en niños requiere al menos 2 de los siguientes 3 criterios: 1) Dolor abdominal sugestivos de PA. 2) Amilasa sérica y/o lipasa de al menos tres veces el límite superior normal. 3) Hallazgos imagenológicos compatibles con PA. ${ }^{3}$ Las infecciones virales se identifican como causa de PA alrededor del $8 \%-10 \%$ de los casos, destacándose los virus de paperas, coxsackie, influenza y Epstein-Barr virus. Otras causas comunes en niños son causas biliares / obstructivas (10\%-30\%), medicamentos (5\%-25\%) y traumatismos. (10\%-20\%). ${ }^{4}$
Se ha informado PA en adultos y niños afectados por SARS-CoV-2. Entre la población pediátrica existen informes de casos aislados de pancreatitis y podría ser una complicación gastrointestinal de COVID-19. ${ }^{5}$ Reporte de casos (ver tabla 1).

A continuación presentamos una serie de 3 casos de pacientes pediátricos atendidos en el Hospital Materno infantil José Domingo de Obaldía en el mes de agosto y noviembre de 2020.

\section{Discusión}

En la literatura los síntomas más frecuentes de la infección por SARS-CoV-2 son fiebre y tos, pero estos no se presentan en más del $50 \%$ de los casos. Los síntomas digestivos se han descrito en pacientes de todas las edades (especialmente en pacientes pediátricos). ${ }^{6}$ Los síntomas gastrointestinales pueden preceder a los síntomas respiratorios, concomitante o luego de estos ${ }^{6} \mathrm{y}$ parecen estar asociados con el pronóstico de COVID-19. ${ }^{2}$ 
SARS-CoV-2 utiliza la enzima convertidora de antigiotensina 2 (ECA-2) como receptor celular, La ECA-2 tiene amplia distribución en el organismo este abunda en el tracto respiratorio, gastrointestinal, incluyendo páncreas, sistema cardiovascular y renal. Los mecanismos de lesión pancreática no están definidos, pero podría ser por: lesión directa del virus en las células acinares por inflamación y edema dando filtración de enzima intracelular con muerte celular ${ }^{2,3}$, otros mecanismos descrito es por aumento de riesgo de trombofilia ${ }^{4}$, lipotoxicidad directa y por medio de tormenta de citocinas. También la lesión pancreática podría ser efecto de los medicamentos usados para la COVID-197. En el caso \#1 la elevación de lipasa se demostró al 2do día intrahospitalario.

La sintomatología predominante en estos 3 casos fue: dolor abdominal, vómitos y diarrea con elevación de las enzimas pancreáticas. En el caso 1, madre con PCR detectado SARS-CoV2 (8/11/2020). Resultado de PCR de paciente no detectado (10/11/2020). Prueba serológica IgG+ SARS-CoV2 (9/11/2020). En el caso 3, PCR en tiempo real del padre resultó positivo (9/11/2020). El PCR en tiempo real del paciente fue negativo. Prueba sérica SARS-CoV2 lgG/lgM: IgG positivo $(11 / 11 / 2020)$. En el caso 1 y 3 , ambos pacientes presentaron pancreatitis postinfecciosa, sugerido por que el PCR para SARS-CoV2 de los hisopados nasales fueron negativas con serología Ig M negativas e lg G positivas para SARS-CoV2 .

En el caso 2 a su ingreso no se consideró realizar amilasa y lipasa, con PCR positivo para SARS-CoV2 de hisopado nasal, y USG con hallazgo sugestivo de inflamación pancreática, reingresó al quinto día de su egreso con descenso de estas. Lo que nos hace pensar en que probablemente presento el cuadro de pancreatitis aguda en la fase activa de la infección.

En los 3 casos se investigó por otras causas infecciosas, logrando documentar sólo en el caso \#1 una infección concomitante por adenovirus (panel respiratorio). Todos los pacientes negaron antecedentes de pancreatitis previa ni enfermedad autoinmune asociada, factores de riesgo genético, sin historia familiar de pancreatitis. No se puede descartar que la pancreatitis en el caso numero 1 pudo haber sido facilitada por el uso de remdesivir como ha sido descrito ${ }^{7}$, en ellos se presentó al 4 día de iniciada esta terapia ${ }^{7}$, en nuestro caso se presentó al segundo día de iniciado el remdesivir ninguno falleció.

Entre las limitaciones de nuestro estudio se encuentran ser de carácter retrospectivo, basado en una vigilancia pasiva susceptible a la variabilidad del observador en la búsqueda de pancreatitis, no se contó con forma estandarizada en la evaluación de los pacientes, limitando la documentación en el expediente clínico de algún otro fármaco o ingesta de sustancias botánicas que puedan facilitar la pancreatitis. Otra limitación fue los escasos laboratorios que permitan descartar otras infecciones concomitantes. A pesar de estas limitantes,
Tabla 1 Características clínicas y de laboratorio de pacientes con pancreatitis aguda asociada a SARS-CoV-2

\begin{tabular}{|c|c|c|c|}
\hline Características & Caso \#1 & Caso \#2 & Caso \#3 \\
\hline Edad & 1.5 años & 6 años & 9 años \\
\hline $\begin{array}{l}\text { Antecedentes } \\
\text { patológicos }\end{array}$ & $\begin{array}{c}\text { Acidosis tubular renal } \\
\text { Bajo peso severo }\end{array}$ & $\begin{array}{l}\text { Estenosis valvular } \\
\text { pulmonar }\end{array}$ & Negado \\
\hline Síntomas & Hiporexia, vómitos. & $\begin{array}{l}\text { Evacuaciones } \\
\text { líquidas, vómitos, } \\
\text { cefalea y fiebre. } \\
\text { Dolor abdominal en } \\
\text { hipogastrio y } \\
\text { mialgias. }\end{array}$ & $\begin{array}{l}\text { Fiebre, vómitos, dolor } \\
\text { abdominal difuso, } \\
\text { evacuaciones diarreicas sin } \\
\text { moco, ni sangre ni } \\
\text { parásitos, hiporexia }\end{array}$ \\
\hline $\begin{array}{l}\text { Prueba para } \\
\text { SARS CoV-2. }\end{array}$ & $\begin{array}{l}\text { PCR no detectado } \\
\text { Prueba serológica: } \\
\text { IgG positiva, IgM } \\
\text { negativa. }\end{array}$ & $\begin{array}{c}\text { plin ueteclauo enl } \\
\text { primera } \\
\text { hospitalización. } \\
\text { Prueba serológica no } \\
\text { realizadac }\end{array}$ & $\begin{array}{l}\text { PCR no detectado. Prueba } \\
\text { serológica: IgG positivo. } \\
\text { IgM negativo }\end{array}$ \\
\hline $\begin{array}{l}\text { Contacto con } \\
\text { COVID-19 }\end{array}$ & $\begin{array}{c}\text { Madre con PCR } \\
\text { detectado }\end{array}$ & $\begin{array}{l}\text { Madre con PCR } \\
\text { detectado }\end{array}$ & Padre con PCR detectado \\
\hline \multicolumn{4}{|l|}{ Bioquímica } \\
\hline Amilasa & $\begin{array}{c}86 \text { U/L, valor máximo } \\
\text { de } 196 \mathrm{U} / \mathrm{L}\end{array}$ & $\begin{array}{c}111 \text { U/L (2da } \\
\text { hospitalización) }\end{array}$ & $\begin{array}{c}227 \mathrm{U} / \mathrm{L}, \text { valor máximo de } \\
283 \mathrm{U} / \mathrm{L}\end{array}$ \\
\hline Lipasa & $\begin{array}{c}975 \mathrm{U} / \mathrm{L} \text {, valor } \\
\text { máximo } 2000 \mathrm{U} / \mathrm{L}\end{array}$ & $\begin{array}{c}304 \text { U/L (2da } \\
\text { hospitalización) }\end{array}$ & $\begin{array}{c}525 \mathrm{U} / \mathrm{L} \text {, valor máximo de } \\
1798 \mathrm{U} / \mathrm{L} .\end{array}$ \\
\hline $\begin{array}{l}\text { Reactantes de } \\
\text { fase aguda }\end{array}$ & $\begin{array}{c}\text { PCR } 8.5 \text { mg/dL, } \\
\text { procalcitonina } 1.2 \text {. } \\
\text { Dímero D: } 516 \\
\text { ng/mL, ferritina } 67 \\
\text { ng/ml. }\end{array}$ & $\begin{array}{l}\text { PCR: } 1.8 \text { mg/dL, VES: } \\
37 \text { mm/hora }\end{array}$ & $\begin{array}{l}\text { Dímero D: } 406 \mathrm{ng} / \mathrm{ml} \text {, } \\
\text { ferritina } 310,10 \mathrm{ng} / \mathrm{ml} \text {. }\end{array}$ \\
\hline ALT & $11 \mathrm{U} / \mathrm{L}$ & $48 \mathrm{U} / \mathrm{L}$ & $38 \mathrm{U} / \mathrm{L}$ \\
\hline Infeccioso & $\begin{array}{l}\text { Adenovirus en } \\
\text { secreción } \\
\text { respiratoria }\end{array}$ & $\begin{array}{l}\text { Negativo por } \\
\text { bacterias }\end{array}$ & Negativo por bacterias \\
\hline Hallazgos USG & $\begin{array}{l}\text { Páncreas no presenta } \\
\text { masas, } \\
\text { calcificaciones, } \\
\text { dilatación del } \\
\text { conducto principal ni } \\
\text { colecciones peri } \\
\text { pancreáticas. }\end{array}$ & $\begin{array}{l}\text { Hepatoesplenomega } \\
\text { lia. Escaso líquida } \\
\text { libre en la fosa de } \\
\text { Morrison. Páncreas } \\
\text { muestra cola } \\
\text { engrosada de } 2 \mathrm{~cm} \text {. }\end{array}$ & $\begin{array}{c}\text { Páncreas muestra } \\
\text { engrosamiento de la cola, } \\
\text { mide } 1,6 \mathrm{~cm} \text {. }\end{array}$ \\
\hline & Remdesivir & Inmunoglobulina & Cefotaxima \\
\hline Tratamiento & $\begin{array}{c}5 \text { días con ventilación } \\
\text { mecánica, } 10 \text { días } \\
\text { con oxígeno } \\
\text { suplementario }\end{array}$ & Cefotaxima & acetaminofén \\
\hline
\end{tabular}

PCR: reacción en cadena de la polimerasa. USG: ultrasonido

estos casos sugieren que la pancreatitis asociada a COVID-19 se debe tener en cuenta en los pacientes pediátricos que consulten con dolor abdominal.

Se necesitan más investigaciones para explorar la posibilidad de la causa de la pancreatitis aguda en niños con COVID-19.

\section{Conclusiones}

Los casos mencionados destacan las manifestaciones de pancreatitis asociados a la COVID-19. Consideramos importante la realización de lipasa y amilasa en pacientes con dolor abdominal considerando a la pancreatitis aguda como una de las posibles complicaciones de este nuevo patógeno. 


\section{Contribuciones de los autores}

Todos los autores contribuyeron a escribir y editar el manuscrito. Todos los autores leyeron y aprobaron el manuscrito final.

\section{Referencias}

1. Scaldaferri F, Laniro GL, Privitera G et al. The thrilling journey of sars-cov-2 into the intestine: From pathogenesis to future clinical implications. Inflamm Bowel Dis. 2020 Aug 20;26(9):13061314. doi: 10.1093/ibd/izaa181. PMID: 32720978; PMCID: PMC7454647.

2. Jiménez DG, Rodríguez-Belvís MV, González PF et al. COVID-19 Gastrointestinal Manifestations Are Independent Predictors of PICU Admission in Hospitalized Pediatric Patients. Pediatr Infect Dis J. 2020 Dec;39(12):e459-e462. doi: 10.1097/ INF.0000000000002935. PMID: 33105340.

3. Parniczky A.EPC/HPSG evidence-based guidelines for the management of pediatric pancreatitis. Pancreatology 2018;18(2):146160. doi: 10.1016/j.pan.2018.01.001. Epub 2018 Jan 4.
4. Alloway BC, Yaeger SK, Mazzaccaro RJ, Villalobos, T, Hardy SG. Suspected case of COVID-19-associated pancreatitis in a child. Radiol Case Rep. 2020 Aug;15(8):1309-1312. doi: 10.1016/j. radcr.2020.06.009. Epub 2020 Jun 6. PMID: 32572339; PMCID: PMC7275143.

5. Shekara S, Sarwara N, Kaliaa M, Castellanos J, Pelliccia F, Gill J. Elevated Lipase Associated With COVID-19 Possibly due to Acute Pancreatitis in a Pediatric Patient: A Case Report. Int J Clin Pediatr. 2020;9(4):125-129. Disponible: https://theijcp. org/index.php/ijcp/article/view/401/347.

6. Nobel YR, Phipps M, Zucker J et al. Gastrointestinal Symptoms and COVID-19: Case-Control Study from the United States, Gastroenterology. 2020;159(1):373-375.e2. doi: 10.1053/j.gastro.2020.04.017. Epub 2020 Apr 12. PMID: 32294477; PMCID: PMC7152871.

7. Khadka S, Williams K, Solanki S. Remdesivir-Associated Pancreatitis. Am J Ther. 2021 Feb 10. doi: 10.1097/ MJT.0000000000001266. 